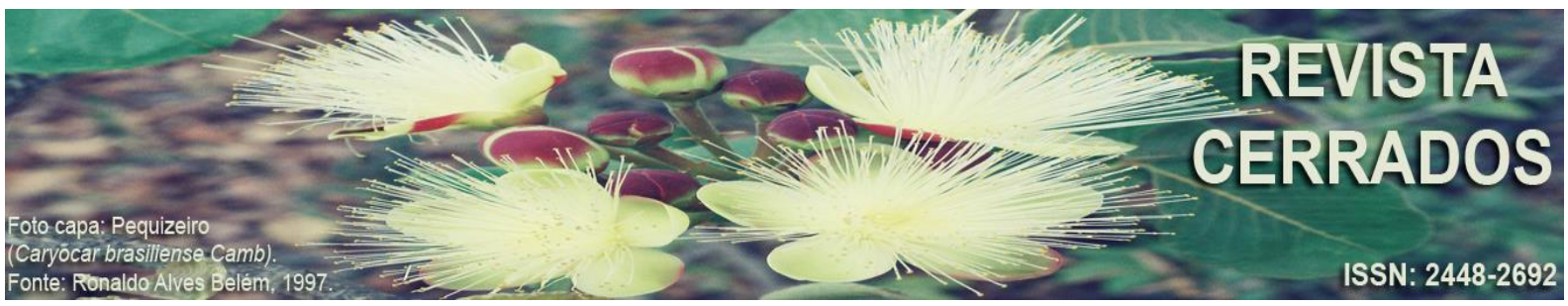

\title{
INDICADORES GEORREFERENCIADOS DE QUALIDADE DE VIDA URBANA: possibilidades para o planejamento urbano ${ }^{1}$
}

\section{GEOREFERENCED INDICATORS OF URBAN QUALITY OF LIFE: possibilities for urban planning}

\section{INDICADORES GEOREFERENCIADOS DE CALIDAD DE VIDA URBANA: posibilidades de planificación urbana}

\author{
Isabela Veloso Lopes Versiani \\ Faculdades Unidas do Norte de Minas - FUNORTE \\ E-mail: <isabelamoc@yahoo.com.br>
}

\begin{abstract}
Resumo
O presente artigo tem como objetivo aprofundar o debate acerca da emergência do tema da qualidade de vida vinculado ao meio urbano e de suas possibilidades para o planejamento urbano. De caráter exploratório, através de pesquisa bibliográfica e documental, o artigo procura delimitar marcos conceituais sobre a qualidade de vida e sua relação com um novo modelo de planejamento urbano a partir do paradigma do desenvolvimento social e de diretrizes do Estatuto da Cidade (2001), além de discutir formas de operacionalização desse conceito tendo como base algumas experiências de construção de sistemas de indicadores de qualidade de vida urbana no Brasil. Como resultados, evidencia-se que a preocupação com a qualidade de vida tem sido expressão recorrente nos debates sobre o presente e futuro das cidades, ganhando espaço e legitimidade a partir de um esforço de delimitação conceitual e de instrumentos para sua mensuração, destacando a contribuição de indicadores georreferenciados para melhor compreensão de desigualdades intraurbanas em diversas áreas. Acredita-se que a incorporação dessa discussão ao planejamento urbano pode contribuir de maneira significativa para pensar e operacionalizar instrumentos que auxiliem no direcionamento de ações e efetivação de políticas públicas para melhoria das condições de vida da população.
\end{abstract}

\footnotetext{
${ }^{1} \mathrm{O}$ presente artigo faz parte do aprofundamento de reflexões sobre o tema da qualidade de vida inserido no planejamento urbano, parcialmente apresentadas no XIV Encontro da Associação Nacional de Pós-Graduação e Pesquisa em Planejamento Urbano e Regional/2011 e no V Congresso em Desenvolvimento Social do PPGDSUNIMONTES/2016, sendo que para a Edição da Revista Cerrados foi reformulado, no qual ampliou-se a discussão atendendo às sugestões dos debatedores.
} 
Palavras-chave: Planejamento Urbano; Indicadores; Qualidade de vida.

\begin{abstract}
This article aims to deepen the debate on the growth of the quality of life theme linked to the urban environment and its possibilities for the urban planning. With exploratory character, through bibliographical and documentary research, the article seeks to define conceptual frameworks on the quality of life and its relationship with a new urban planning model from the social development paradigm and the "City Statute" guidelines (2001), besides discussing ways of operationalizing this concept, basing on experiences of previously existing systems of urban quality of life indicators in Brazil. As a result, it is clear that the concern for quality of life has been a recurring point in discussions regarding the present and future of cities, gaining ground and legitimacy from efforts of conceptual delimitation and tools for its measurement, highlighting the contribution of georeferenced indicators for a better understanding of intraurban inequalities in many areas. It is believed that the incorporation of this discussion into urban planning can contribute significantly to think and operationalize instruments that can help to direct actions and execution of public policies to improve the living conditions of the population.
\end{abstract}

Keywords: Urban Planning; Indicators; Quality of life.

\title{
Resumen
}

En este artículo se pretende profundizar el debate sobre el surgimiento del tema de la calidad de vida relacionado con el ambiente urbano y sus posibilidades para la planificación urbana. De carácter exploratorio, a través de la investigación bibliográfica y documental, el artículo busca definir los marcos conceptuales de la calidad de vida y su relación con un nuevo modelo de planificación urbana desde el paradigma del desarrollo social y las directrices del Estatuto de la Ciudad (2001), además de discutir maneras de hacer operativo este concepto basado en algunas experiencias en la construcción de sistemas de indicadores de calidad de vida urbana en Brasil. Como resultado de ello, es evidente que la preocupación por la calidad de vida ha sido una expresión recurrente en los debates sobre el presente y futuro de las ciudades, ganando terreno y legitimidad a través de esfuerzos de delimitación conceptual y herramientas para su medición, destacando la contribución de indicadores georeferenciados para una mejor comprensión de las desigualdades intra-urbanas en muchas áreas. Se cree que la incorporación de esta discusión a la planificación urbana puede contribuir significativamente a pensar y operar instrumentos que ayudan a dirigir las acciones y ejecución de políticas públicas para mejorar las condiciones de vida de la población.

Palabras-clave: Planificación urbana, indicadores, calidad de vida. 


\section{INTRODUÇÃO}

Os reflexos da produção capitalista do espaço urbano conduziram o desenvolvimento urbano brasileiro por um caminho centrado na dimensão econômica que, se por um lado foi importante para o crescimento industrial e expansão do consumo individual de bens e serviços no país, por outro, contribuiu para o aumento dos problemas ambientais, da exclusão social, da carência de serviços públicos urbanos de qualidade, aumento da violência, entre outros. Essas situações coexistem em muitas cidades brasileiras com grande intensidade, agravadas pelo fato de se concentrarem espacial e socialmente em sua dimensão intraurbana, reproduzindo desigualdades e ampliando contradições.

Diante desse quadro, uma compreensão de cidade vinculada à dimensão social e política das contradições que moldam o cotidiano urbano torna-se fundamental para pensar e implementar formas para melhorar as condições de vida de seus habitantes e ampliar a cidadania no planejamento urbano, na qual as novas diretrizes e instrumentos do Estatuto da Cidade (2001) representam um avanço no debate para a efetivação do direito à cidade, da função social da propriedade e da melhoria da qualidade de vida de seus habitantes.

A área da qualidade de vida urbana tem se desenvolvido em todas as partes do mundo, principalmente a partir de sistemas de indicadores articulados em torno de redes de cidades, movimentos da sociedade civil e governos municipais, com o objetivo de contribuir para uma melhor compreensão das necessidades de seus habitantes e das especificidades socioespaciais em seu interior, direcionando metas e ações no âmbito do planejamento urbano e das políticas públicas.

É justamente com referência à busca de uma melhor qualidade de vida para as cidades brasileiras que se aprofunda a discussão aqui proposta. Da discussão global às implicações locais, o tema da qualidade de vida tem sido uma problemática emergente que interfere no presente e futuro das cidades, porém, como um campo recente de estudos, ainda carece de delimitações conceituais e empíricas bem definidas para sua operacionalização no meio urbano.

Nesse contexto, o artigo busca aprofundar o debate acerca da inserção dessa temática no meio urbano, procurando identificar marcos conceituais sobre a qualidade de vida e sua relação com o planejamento urbano, além de formas de operacionalização desse conceito através da construção de indicadores. 
De caráter exploratório, utiliza-se de pesquisa bibliográfica e documental para evidenciar, em um primeiro momento, discussões em torno do surgimento de um outro modelo de planejamento urbano, amparado pela inserção do paradigma do desenvolvimento social e novas diretrizes e instrumentos do Estatuto da Cidade (2001), relacionando-as com o tema da qualidade de vida. Em um segundo momento, procura estabelecer marcos conceituais acerca da qualidade de vida e sua inserção no meio urbano, destacando formas de operacionalização desse conceito a partir de algumas experiências de construção de sistemas de indicadores de qualidade de vida urbana no Brasil, dando centralidade às suas contribuições para direcionar ações de planejamento na busca pela redução de desigualdades intraurbanas e, consequentemente, na promoção de melhores condições de vida para toda a população.

\section{Em busca de outro modelo de planejamento urbano: o resgate da dimensão social}

Vinculado ao modo de produção capitalista, o processo de urbanização é marcado por aspectos contraditórios próprios à gênese do capitalismo, que influem na configuração de diversos conflitos entre segmentos sociais, destacando-se implicações na produção do espaço pelos interesses capitalistas, emergência de demandas urbanas coletivas e ações mediadoras do Estado, principalmente em relação aos bens de consumo coletivo ("bens de cidadania"), essenciais à melhoria da qualidade de vida.

A compreensão do espaço urbano como efeito da articulação de múltiplas relações e práticas que movimentam a sociedade gera conflitos que se evidenciam, principalmente, na desigual ocupação e uso do solo urbano; na contradição entre a produção socializada do espaço e sua apropriação privada ou entre seu valor de uso e seu valor de troca, reflexo da regulação das trocas de mercadorias do capitalismo na dimensão territorial.

Nessa lógica, tem-se como consequência a supervalorização da rentabilidade econômica na reprodução do capital, com ausências e ineficiências no campo dos meios de consumo coletivo, o que compromete a promoção de melhores condições de vida no âmbito urbano, especialmente dos mais pobres. Para buscar modificar esse quadro, é importante considerar a análise do espaço urbano como palco privilegiado para transformação dessas crescentes contradições, vinculando-o essencialmente a uma posição política, em que os 
papéis do Estado (Poder Público) e das reivindicações sociais no urbano assumem centralidade no debate necessário para promover mudanças.

Mesmo permeado por limites neoliberais e centralizando as contradições capitalistas no processo de urbanização, o papel do Estado na organização política do espaço não pode ter sua função restrita aos interesses de setores privados hegemônicos. A dimensão política do espaço urbano também pode ser lugar da luta por demandas que atendam a necessidades básicas da população, numa perspectiva contra-hegemônica, a partir de múltiplas determinações sociais na configuração do urbano no cotidiano, que o transforma em espaço de resistência e socialização, de residência e convivência, de mobilidade e liberdade, de oportunidades e acesso a equipamentos urbanos, de realização dos direitos sociais; enfim, da esfera do consumo coletivo dos bens e meios que são essenciais à melhoria da qualidade de vida de qualquer cidadão urbano.

Para Lefèbvre (2008), a impossibilidade do urbano para todos só pode ser superada através da prática social e de uma "urbanização crítica", fazendo retornar o valor do uso para além do valor da troca e, assim, promover a realização da vida urbana, que não elimina o confronto e a luta, mas, pelo contrário, enseja uma nova produção social do espaço em busca do direito à cidade.

A contra-hegemonia da dimensão política no urbano, amparada pelas crescentes reivindicações coletivas, tem ensejado processos de reformas e mudanças, mesmo que lentas, na direção de novos modelos de desenvolvimento urbano que priorizam o espaço do viver e, consequentemente, resultam em novas configurações sociais do quadro urbano. Tal processo perpassa a produção do espaço aliada à prática social, preocupada com o atendimento das especificidades e necessidades da população através de um planejamento urbano participativo, em detrimento de uma produção material do espaço apoiada no planejamento tecnicista.

Com reflexos no contexto urbano brasileiro, o rearranjo institucional e político decorrente da redemocratização do país, associado às pressões dos movimentos sociais, possibilitaram um ambiente favorável para mudanças significativas no trato das principais questões da política urbana, e, com a Constituição de 1988, criaram-se as bases para o desenvolvimento de uma reforma urbana através dos artigos 182 e 183. A política urbana começava a ganhar contornos mais consistentes com o objetivo de solucionar uma série de desequilíbrios no quadro urbano brasileiro, apontando a busca pela reestruturação das cidades a partir da perspectiva democrática e de um novo modelo de planejamento. 
O Estatuto da Cidade foi aprovado pelo Congresso Nacional em 2001, através da Lei n. 10.257/01, para regulamentar os referidos artigos 182 e 183 do capítulo da política urbana inserido na Constituição Federal desde 1988. Tal estatuto tem como função básica garantir o pleno desenvolvimento da cidade, baseando-se nas funções sociais da cidade e da propriedade, através do estabelecimento de "normas de ordem pública e interesse social que regulam o uso da propriedade urbana em prol do bem coletivo, da segurança e do bem-estar dos cidadãos, bem como do equilíbrio ambiental" (BRASIL, 2001). Além disso, busca estabelecer as diretrizes para que um modelo de gestão democrático e participativo seja incorporado às cidades.

Dessa forma, o Estatuto da Cidade (2001) pretende ser um novo padrão para a política urbana, principalmente com relação à formulação de instrumentos jurídicos e urbanísticos que garantam uma nova lógica de universalização do acesso aos serviços e equipamentos urbanos; uma gestão para as cidades que priorize a dimensão política de participação de seus habitantes nos processos de planejamento; além da prevalência do interesse social sobre os interesses particulares que resulte na construção de um espaço urbano mais justo e equilibrado.

A superação da centralização da dimensão técnica no planejamento, através das novas possibilidades de intervenção do Estatuto da Cidade, desenvolve-se com a ampliação da gestão democrática, na qual a população se envolve diretamente na organização da cidade, aproximando-se da esfera política através da participação em conselhos de política urbana, na proposição de projetos, nas decisões relativas aos Planos Diretores e leis orçamentárias, entre outras.

Nesse processo de regulamentação, o direito à cidade é visto a partir de uma dimensão ampla, legitimado pelo direito de uso e ocupação do solo urbano, ao saneamento básico, à infraestrutura urbana, aos serviços públicos, ao acesso ao mercado de trabalho, ao lazer, entre outros, integrado a mecanismos sociais de incremento da qualidade de vida, passando a exigir a redefinição de espaços urbanos, novas práticas de cidadania e reformulações de políticas públicas específicas no direcionamento das ações de planejamento urbano.

Embora o Estatuto da Cidade seja estruturado através de instrumentos urbanísticos, econômicos e jurídicos para promover "a garantia de direitos, a gestão democrática das cidades e a equidade social com a justa distribuição de benefícios e ônus 
decorrentes do processo de urbanização" (CARVALHO, 2009, p.52), sua execução na atual conformação socioespacial, tanto das grandes cidades brasileiras como, recentemente, nas cidades médias, tem sido um intenso desafio.

O alcance social das políticas urbanas ainda se encontra distante da garantia de bem-estar dos cidadãos e acesso à cidade, em que se reconhece o peso da exclusão e segregação socioespacial, bem como de disputas entre os segmentos sociais acerca de suas necessidades e interesses. Para Ribeiro e Cardoso (1989 apud CARVALHO, 2009, p. 62):

\begin{abstract}
De forma simplificada, esses interesses reúnem, de um lado, os cidadãos ou grupos que, por deterem parcelas da riqueza social, têm algo a ser preservado ou acrescentado. De outro lado, estão os setores sociais que desde sua origem são desiguais, dada a forma como estão inseridos nos processos de produção e apropriação da riqueza social. Esses últimos se identificam às camadas populares da sociedade, cujas estratégias de sobrevivência constituem-se nas evidências urbanas das situações de conflito. Trata-se de parcelas da população que, uma vez expulsas ou segregadas, habitam favelas ou cortiços, em periferias urbanas com limitações de acesso a serviços e equipamentos coletivos e, muitas vezes, em situações de irregularidade em relação à posse e propriedade da terra.
\end{abstract}

Apesar do Estatuto da Cidade representar uma possibilidade de contestação e inovação, em direção a um outro modelo de planejamento urbano, é uma lei que ainda carece de força e implementação prática. Segundo Maricato (2003), uma das principais dificuldades é a aplicação, de fato, dos novos instrumentos urbanísticos, sobretudo quando se deseja reestruturar o quadro de produção espacial fazendo cumprir a função social da propriedade, o que diminuiria o lucro especulativo.

Nesse ponto, evidenciam-se impasses no que se refere ao papel do Estado e suas ações para prover acesso aos "bens de cidadania", e às lutas urbanas cotidianas dos estratos sociais mais pobres. Notadamente, na dificuldade do Estado em dar materialidade às intervenções públicas para reduzir os efeitos dessas contradições no espaço urbano.

Para Lefèbvre (2008), os custos sociais da negação do direito à cidade são muito mais elevados que os de sua realização, embora esse não seja o discurso predominante. Para o autor, a superação desses impasses dependeria de uma mudança profunda das relações sociais a partir de um modo de produção transformado, no qual a gestão e produção coletiva do espaço fossem orientadas para o desenvolvimento social como seu fim último.

O direito à cidade, tomado em toda a sua amplitude, aparece hoje como utopiano [...] Os custos podem parecer exorbitantes, sobretudo se contabilizados nos marcos administrativos e burocráticos atuais. [...] É óbvio que só um grande crescimento da riqueza social, ao mesmo tempo que profundas modificações nas próprias relações 
sociais (no modo de produção), pode permitir a entrada, na prática, do direito à cidade e de alguns outros direitos do cidadão e do homem. Um tal desenvolvimento supõe uma orientação do crescimento econômico, que não mais conteria em si sua "finalidade", nem visaria mais a acumulação (exponencial) por si mesma, mas serviria a "fins" superiores (LEFÈBVRE, 2008, p.34).

Aplicada à realidade cotidiana das cidades brasileiras, a implantação de normas urbanísticas que servem a "fins" superiores se encontra defasada em relação aos usos urbanos e necessidades da população. Embora possam estar sinalizadas nessa nova modalidade de planejamento, as necessidades de parcela da população não são efetivadas na prática, ficando restritas às normas jurídicas de concepção do planejamento público, distantes da sua gestão por meio de instrumentos urbanísticos e formas de apropriação social do espaço.

Invariavelmente, prevalecem impasses entre um modelo de gestão participativo, visando o bem-estar coletivo, e o tecnicismo - ainda predominante na execução do planejamento brasileiro - principalmente quando orientado para a satisfação de demandas corporativas, especialmente as imobiliárias, em detrimento da qualidade de vida da maioria da população no espaço urbano do país.

Frente às dificuldades, o debate acerca da implementação, de fato, desse novo modelo de planejamento urbano tem se ampliado e fortalecido, principalmente quando associado à perspectiva da qualidade de vida, temática tão presente hoje em dia nos mais variados campos. Nos dizeres de Lefèbvre (2008, p.150), diante da constatação de um crescente mal-estar que desperta a consciência de que "em meio à prosperidade capitalista relativa e ao crescimento da produção, há muita insatisfação", muitas pessoas passaram a referir-se à qualidade de vida, qualidade do espaço ou com o querer mudar a vida.

A preocupação com a qualidade de vida tem relação direta com a qualidade do espaço, esta última entendida a partir da idéia de um "um espaço social elaborado, complexo e exitoso, numa palavra, apropriado, e não somente dominado pela técnica e pelo poder político; o que estaria associado com o mudar a vida "(LEFÈBVRE, 2008, p. 150).

Para proporcionar essa mudança, Lefèbvre (2008) destaca que o crescimento econômico e o desenvolvimento social não podem mais se confundir e, apesar de durante muito tempo ter-se acreditado que o crescimento indefinido da produção e da produtividade levaria ao desenvolvimento qualitativo, é preciso reconhecer que o crescimento quantitativo não levou a satisfação das principais necessidades.

Quando associada à busca de soluções para os problemas urbanos, a preocupação com a qualidade de vida passa a envolver uma mudança de valores acerca da forma como as 
cidades têm se estruturado e relaciona-se diretamente a um modelo de desenvolvimento urbano que prioriza a justiça social, a ampliação de oportunidades e a melhoria das condições de vida da população, aproximando a cidadania do cotidiano urbano.

Como um novo paradigma aliado à busca de um maior desenvolvimento social nas cidades, a temática da qualidade de vida urbana em interface com o planejamento urbano constitui-se em um campo recente de estudos, que pode contribuir para o direcionamento de ações integradas da política urbana com outras políticas públicas, perfazendo uma nova forma de pensar e viver nas cidades, que tem se ampliado a partir da construção de indicadores para sua mensuração.

\section{Construção de indicadores de qualidade de vida urbana}

Quando se pretende aprofundar o tema da qualidade de vida urbana relacionado à criação de indicadores sociais para viabilizar sua mensuração e aplicação no âmbito urbano, faz-se necessário esclarecer alguns aspectos conceituais importantes, dentre eles, o próprio entendimento do que seja um indicador. Segundo Januzzi (2009, p.133), indicador social é:

\footnotetext{
Uma medida em geral quantitativa dotada de significado social substantivo, usado para substituir, quantificar ou operacionalizar um conceito social abstrato, de interesse teórico (para a pesquisa acadêmica) ou programático (para formulação de políticas). É um recurso metodológico, empiricamente referido, que informa algo sobre um aspecto da realidade social ou sobre mudanças que estão se processando na mesma. Os indicadores sociais se prestam a subsidiar as atividades de planejamento público e formulação de políticas sociais nas diferentes esferas de governo, possibilitam o monitoramento das condições de vida e bem-estar da população por parte do poder público e sociedade civil e permitem aprofundamento da investigação acadêmica sobre a mudança social e sobre os determinantes dos diferentes fenômenos sociais.
}

No mesmo sentido, Herculano (1998, p.11) expõe que "os indicadores constituem informações condensadas, simplificadas, quantificadas, que facilitam a comunicação, comparações e o processo de decisão". No campo social, a mesma autora coloca que "os indicadores sociais propõem-se, ainda, a ser um incentivo para a mobilização da sociedade a fim de pressionar os que tomam as decisões", sendo úteis para a construção de um futuro mais desejável.

A construção desses indicadores não é simples e envolve uma série de escolhas, que irão influenciar as propriedades e critérios selecionados para sua operacionalização, de 
acordo com a aplicação a que se destinam e a área temática a que se referem. Dentre essas propriedades e critérios, Januzzi (2002, p.55-56) aponta que:

\begin{abstract}
Além de sua relevância para a discussão da agenda da política social, de sua validade em representar o conceito indicado e da confiabilidade dos dados usados na sua construção, um indicador social deve ter um grau de cobertura populacional adequado aos propósitos a que se presta, deve ser sensível a políticas públicas implementadas, específico a efeitos de programas setoriais, inteligível para os agentes públicos-alvo das políticas, atualizável periodicamente, a custos factíveis, ser amplamente desagregável em termos geográficos, sociodemográficos e socioeconômicos e gozar de certa historicidade para possibilitar comparações no tempo.
\end{abstract}

A década de 1960 é considerada por muitos pesquisadores como o marco inicial na construção de indicadores sociais devido às tentativas de organização de sistemas de informações mais abrangentes acerca das condições de vida das populações de países desenvolvidos e subdesenvolvidos, em contraposição à ênfase que era dada ao crescimento econômico, que restringia a compreensão das transformações e impactos das políticas de desenvolvimento na realidade social, principalmente dos países e populações mais pobres.

Apesar desses esforços, Januzzi (2009) aponta que, somente em meados da década de 1980, o campo dos indicadores sociais passou a ser associado intrinsecamente com a consolidação de atividades de planejamento do setor público, aprimorado por esforços conceituais e metodológicos que resultaram em novas experiências de formulação e implementação de políticas públicas, bem como por iniciativas de Universidades, sindicatos, centros de pesquisa e agências vinculadas a Sistemas de Planejamento Público.

Para Januzzi (2002), esse campo, no Brasil, tem sido influenciado na última década pela descentralização administrativa e tributária em favor dos municípios e da institucionalização do processo de planejamento público em âmbito local pela Constituição de 1988, o que favorece uma crescente demanda por informações sociais e demográficas para fins de formulação de políticas públicas municipais, e desenvolvimento de sistemas de estatísticas municipais com interfaces para sistemas georreferenciados.

Diversos municípios de médio e grande porte passaram a demandar com maior frequência uma série de indicadores sociodemográficos às agências estatísticas, empresas de consultoria e outras instituições ligadas ao planejamento público, com o objetivo de subsidiar a elaboração de planos diretores de desenvolvimento urbano, de planos plurianuais de investimentos, para permitir a avaliação dos impactos ambientais decorrentes da implantação de grandes projetos, para justificar o repasse de verbas, para disponibilizar equipamentos ou serviços sociais para públicos específicos por exigência legal (para portadores de deficiências, por exemplo) ou por 
pressão política da sociedade local (melhoria dos serviços de transporte urbano, por exemplo) (JANUZZI, 2002, p. 53).

Porém, Januzzi (2002, p.70) chama a atenção para o fato de que os indicadores sociais possuem limites que podem estar relacionados à baixa capacidade técnica dos gestores para operacionalizá-los, à ineficiente cobertura espacial das análises, à construção de variáveis muito sintéticas que prejudicam a compreensão real das diferenças, entre outros, que devem ser levados em consideração na definição de prioridades sociais e na alocação de recursos do orçamento público, mas que, se bem empregados, "podem enriquecer a interpretação empírica da realidade social e orientar de forma mais competente a análise, a formulação e a implementação de políticas". Outro limite, para o autor (2002), é que não se deve superestimar o papel e a função desses indicadores, pois apenas o fato de terem sido produzidos não é suficiente para garantir a formulação e implementação das políticas, já que estas dependerão da mobilização e do papel desempenhado pelos agentes responsáveis pela sua execução.

Relacionados à problemática da qualidade de vida como uma forma mais abrangente para agrupar temas que compõem o universo da realidade social no âmbito urbano, sistemas de indicadores de qualidade de vida urbana têm se desenvolvido para auxiliar o setor público, principalmente nas atividades de diagnóstico dos problemas, carências e necessidades das cidades e de suas populações e, consequentemente, influenciar processos de tomada de decisão, áreas prioritárias para investimento, alocação de recursos, atendimento a demandas, entre outros.

As discussões em torno da mensuração da qualidade de vida guardam relação direta com o debate travado entre modelos de desenvolvimento e a busca por novos indicadores capazes de ampliar a compreensão da qualidade de vida para além da esfera econômica, com o intuito de agregar outros elementos que permitam o alcance de uma vida mais digna para todos os indivíduos.

Ao aproximar a temática da qualidade de vida urbana à construção de sistemas de informações como instrumentos para subsidiar ações de planejamento urbano e direcionamento de políticas públicas, dois aspectos metodológicos são fundamentais: no primeiro, deve-se construir uma racionalização do conceito de qualidade de vida com o objetivo de operacionalizar a busca por indicadores válidos; no segundo, deve-se definir o 
local ao qual o objeto de pesquisa se vincula para proceder à realização de diagnósticos e análises territorializados.

Em função de sua complexidade, definir o tema da qualidade de vida coloca-se como um desafio particular, pois abrange diferentes abordagens e problemáticas. A expressão qualidade de vida não é nova, mas a sistematização da área enquanto campo de pesquisa em sua totalidade pode ser considerada como um fenômeno recente.

O campo da saúde foi o que mais se utilizou da pesquisa relacionada à qualidade de vida, principalmente no que se refere ao tratamento de pacientes com problemas crônicos de saúde; avaliação e decisão nas intervenções médicas e efeitos de determinados medicamentos nos indivíduos (YUAN; YUEN; LOW, 1999). Nos últimos anos, essa expressão ganhou cada vez mais espaço em outros campos de pesquisa e, particularmente, no campo do desenvolvimento, envolvendo a dimensão econômica, ambiental, social e urbana, e contemplando aspectos individuais, coletivos, materiais, imateriais, objetivos e subjetivos.

Embora a preocupação com a qualidade de vida tenha se incorporado em alguns discursos políticos e sociais a partir da década de 1960, no bojo do modelo economicista predominante, foi a busca pela elevação do PIB per capita que se impôs como referência nas décadas seguintes e superou a discussão da necessidade de mudanças quantitativas e qualitativas na forma como as questões relativas às condições de vida vinham sendo tratadas, principalmente das populações pobres.

Recentemente, com o agravamento dos problemas propiciados por esse modelo, a temática da qualidade de vida voltou a ganhar destaque, vinculada, principalmente, à dimensão ambiental e social no contexto urbano. Muitos estudos e pesquisas passaram a problematizar seu conceito e sua repercussão em relação a essas áreas, sendo consenso entre os pesquisadores notar a complexidade envolvida na delimitação de seus principais aspectos.

De fato, definir qualidade de vida não é uma tarefa simples, sobretudo se levarmos em consideração sua dimensão individual, pessoal e subjetiva - vinculada às diferentes percepções, valores, necessidades e desejos relacionados em uma mesma situação que variam segundo condições culturais, temporais e espaciais diferenciadas.

Um primeiro passo, para maior delimitação, é compreender que a qualidade de vida está diretamente associada a uma melhoria no bem-estar das pessoas, tanto no plano individual quanto no coletivo e, nesse sentido, segundo Marques (2007), não pode ser analisada como algo a ser alcançado que depende exclusivamente da atitude individual do 
sujeito em mudar seus hábitos, mas deve centrar-se na busca por alternativas para a melhoria do nível de vida do maior número de pessoas possível, e isso não depende só do sujeito.

Como forma de buscar sistematizar esse universo, a construção da compreensão da qualidade de vida tem-se desenvolvido com referências, concepções, construção de indicadores e procedimentos metodológicos vinculados a dois campos principais: o que envolve aspectos objetivos e o dos aspectos subjetivos.

\begin{abstract}
Pontos de vista objetivos buscam uma análise ou compreensão da realidade pautada em elementos quantificáveis e concretos, que podem ser transformados pela ação humana. A análise desses elementos considera fatores como alimentação, moradia, acesso à saúde, emprego, saneamento básico, educação, transporte, ou seja, necessidades de garantia de sobrevivência próprias da sociedade contemporânea. Essa perspectiva se caracteriza como uma busca por dados quantitativos e qualitativos que permitem traçar um perfil de um indivíduo ou grupo em relação ao seu acesso a bens e serviços [...]. Com esse tipo de tratamento, torna-se possível estabelecer quadros de perfis socioeconômicos para ações voltadas à melhoria da Qualidade de Vida para os sujeitos envolvidos. A análise da Qualidade de Vida sob um aspecto subjetivo também leva em conta questões de ordem concreta, porém, considera variáveis históricas, sociais, culturais e de interpretação individual sobre as condições de bens materiais e serviços do sujeito. Não busca uma caracterização dos níveis de vida apenas sobre dados objetivos, mas relaciona-os com fatores subjetivos como emocionais, expectativas e possibilidades dos indivíduos ou grupos em relação às suas realizações, e a percepção que os atores têm de suas próprias vidas, considerando, inclusive, questões imensuráveis como prazer, felicidade, angústia e tristeza (MARQUES, 2007, p.23).
\end{abstract}

A ênfase que aqui será conferida à esfera objetiva da qualidade de vida, assim como de seus instrumentos e indicadores, não desconsidera a importância da esfera subjetiva nesse processo. Embora essas duas dimensões sejam complementares e difíceis de serem analisadas separadamente, a opção por priorizar a discussão com referência à percepção da qualidade de vida mais próxima de seus aspectos objetivos justifica-se pelas enormes dificuldades que o nosso país tem em oferecer acesso integral à população aos bens e serviços que compõem esse campo, principalmente na dimensão do consumo de bens coletivos.

A compreensão da associação da qualidade de vida à efetivação de oportunidades e escolhas pelos indivíduos, através de realizações coletivas, também a aproxima de uma posição política que, no contexto urbano, reflete-se nos direcionamentos para ações de planejamento urbano e políticas públicas que contribuam para sua melhoria e ampliação, em estreita ligação com seus aspectos objetivos.

Essa perspectiva recente é enfatizada por Herculano (1998) pela sua possibilidade em tornar o conceito de qualidade de vida um instrumental sociológico, um novo campo não 
só de estudos, mas de intervenção, definido pelo estudo substantivo, descritivo e normativo das condições de vida social, econômica e ambiental. O conceito de qualidade de vida é então explicitado como:

[...] a soma das condições econômicas, ambientais, científico-culturais e políticas coletivamente construídas e postas à disposição dos indivíduos para que estes possam realizar suas potencialidades: inclui a acessibilidade à produção e ao consumo, aos meios para produzir cultura, ciência e arte, bem como pressupõe a existência de mecanismos de comunicação, de informação, de participação e de influência nos destinos coletivos, através da gestão territorial que assegure água e ar limpo, higidez ambiental, equipamentos coletivos urbanos, alimentos saudáveis e a disponibilidade de espaços naturais amenos urbanos, bem como a preservação de ecossistemas naturais (HERCULANO, 1998, p. 17).

Efetivar essas condições nas cidades para que seus habitantes possam realizar suas potencialidades e atingir uma maior qualidade de vida tem sido cada vez mais difícil. As diferenças marcantes e constitutivas de espaços segregados nas cidades brasileiras distanciam esse conceito de uma dimensão realmente cidadã no urbano.

É justamente nesse ponto que Vitte (2002) retoma a importância da política em ocupar lugar central na discussão sobre o presente e o futuro das cidades e da cidadania como ação coletiva, afirmativa e cotidiana na construção e efetivação de direitos, dando centralidade à questão social no debate sobre políticas de intervenção no espaço urbano e práticas de planejamento urbano na atualidade. Para a mesma autora, a discussão sobre qualidade de vida passa a ser uma das premissas norteadoras do desenvolvimento e do bemestar, devendo ser considerada como um direito de cidadania.

Nessa perspectiva, outra importante contribuição é dada por Souza (2008), para quem uma das tarefas ao se lidar com o planejamento e a gestão urbanos como pesquisa social aplicada é a de integrar a reflexão sobre aquilo que, sinteticamente, deve ser a finalidade do planejamento e da gestão - o desenvolvimento urbano, ou a mudança social positiva da e na cidade.

Para Souza (2008), o desenvolvimento urbano é entendido como desenvolvimento socioespacial pensado a partir de dois pilares complementares: um aumento da justiça social e uma maior qualidade de vida, enfatizando a busca por maior autonomia individual e coletiva das pessoas como determinante desse processo e uma análise que contemple não só as relações sociais, mas, igualmente, a espacialidade na discussão. 
A partir dessa visão, no trato de discussões teórico-metodológicas acerca da qualidade de vida e de sua relação com o planejamento e gestão urbanos, partilhar-se-á da ideia destacada por Vitte e Keinert (2009, p.10) de que, embora a análise da qualidade de vida possa se legitimar no debate por sua dimensão objetiva, individual e, mais recentemente, subjetiva, opta-se por concentrar esforços no avanço da análise da dimensão política da qualidade de vida, que "envolve aspectos relativos ao planejamento e às práticas de gestão pública, à democracia, ao fortalecimento da cidadania, à luta e garantia dos direitos fundamentais da pessoa, bem como dos direitos sociais".

A qualidade de vida urbana, então, passa a ser apreendida não apenas em nível pessoal ou de uma dimensão individual e subjetiva, mas vincula-se diretamente à sua dimensão coletiva. Levando-se em conta o grau de adequação das características espaciais, ambientais e sociais da cidade às metas, planos e aspirações dos indivíduos, o que deverá ser priorizado é a ligação da qualidade de vida com o desenvolvimento urbano no sentido de aproximá-la ao cotidiano de seus habitantes, com o objetivo de efetivar suas capacidades e ampliar suas possibilidades de escolhas em um ambiente urbano mais justo, humano, cidadão e ambientalmente sustentável.

Dada a ênfase na dimensão política, a qualidade de vida urbana legitima a preocupação com questões que interferem diretamente nas condições de vida e bem-estar da população urbana, principalmente a partir da garantia de acesso ao consumo de bens coletivos, abarcando áreas que envolvem não só aspectos econômicos, mas também, sociais, ambientais, de cidadania, de serviços urbanos, de habitação, de mobilidade e transporte, de segurança, de educação, de saúde, de lazer, entre outros.

Assim, a melhoria da qualidade de vida da população tem ligação direta com o atendimento de demandas sociais e várias têm sido as tentativas de construção de instrumentos para sua mensuração no âmbito urbano. Através de sistemas de indicadores de qualidade de vida urbana, muitas cidades, por iniciativa de seus gestores públicos ou organizações da sociedade civil, buscam inserir essa temática no desenvolvimento de ações estratégicas para o direcionamento do planejamento e políticas públicas relacionadas às diversas áreas, principalmente através de diagnósticos de desigualdades intraurbanas.

Esses sistemas, em essência, se desenvolvem com base em metodologias preocupadas em construir diferentes indicadores para comparar regiões de uma mesma cidade, redes de cidades ou países, com o objetivo de aprimorar técnicas de mensuração e 
compartilhar experiências no âmbito do planejamento urbano e das políticas públicas que dependem do real conhecimento dos problemas a serem enfrentados para sua eficácia.

Por ser uma temática complexa, a racionalização do conceito de qualidade de vida no âmbito urbano é essencial para operacionalização de seus indicadores. Ao discutir a proposta de criação do Observatório de Qualidade de Vida de Santo André (OQVSA), no Estado de São Paulo, os autores envolvidos no processo entendem por operacionalização "a busca de indicadores concretos, empíricos, capazes de traduzir e permitir encontrar na prática os conceitos teóricos e as variáveis envolvidas na temática em questão", com o objetivo de alcançar uma definição concreta na qual se referencie os indicadores para medi-la (KARRUZ; KEINERT, R; KEINERT, T., 2002, p. 96).

Ainda para esses autores, no caso do OQVSA, e também de outros, faz parte do delineamento conceitual acerca da implantação do sistema de informações sobre qualidade de vida urbana reconhecer que certo reducionismo na definição conceitual é necessário, pois "a transformação de um conceito em um indicador invariavelmente implica uma perda, a qual deve-se estar disposto a bancar, caso contrário não se terá indicadores e não se poderá aferir a QV em determinada localidade” (KARRUZ; KEINERT, R; KEINERT, T., 2002, p. 97).

Para Nahas (2008, p. 96), quando se trata da formulação de indicadores para instrumentalizar o planejamento urbano - particularmente no nível municipal - "o conceito de qualidade de vida urbana resulta do enfoque no desenvolvimento das cidades e seus problemas socioambientais e da necessidade de monitorar seu desenvolvimento no nível local", levando-se em consideração, sobretudo, o contexto em que as pessoas vivem com o objetivo de captar, não só, o acesso social a determinados bens e serviços - entendido como o reflexo do acesso a "bens de cidadania", "considerados essenciais à satisfação das necessidades básicas de uma sociedade num determinado período de tempo" - mas também, expressar a oferta de serviços no espaço, desenvolvendo uma abordagem espacial do acesso da população a tais bens, "sinalizando a localização geográfica dos mesmos".

Para a mesma autora, a formulação de indicadores urbanos que avaliem a oferta disponível para a população, enfatizando a acessibilidade, possibilita ao poder público identificar "prioridades setoriais e também espaciais, para que suas políticas, programas e investimentos resultem em melhoria da qualidade de vida que a cidade oferece a seus moradores"; embora esbarre na dificuldade de lidar nas grandes cidades, e também, mais 
recentemente nas cidades médias, "com as profundas diferenças em seu interior, nos mais diversos aspectos" (NAHAS, 2008, p.96).

\begin{abstract}
Nessa situação, torna-se indispensável a construção de indicadores georreferenciados no espaço intraurbano, permitindo também ao gestor público local a identificação de prioridades espaciais para certos investimentos, especialmente localização de equipamentos sociais que promovam um acesso equitativo a serviços e bens, promovendo a inclusão e a equidade (NAHAS, 2008, p.96).
\end{abstract}

Destaca-se, nesse ponto, o outro fundamento metodológico indispensável à construção de indicadores de qualidade de vida urbana. Através da realização de diagnósticos e análises territorializados, o espaço urbano passa a ser compreendido a partir das diferenças que conformam a acessibilidade desigual a bens e serviços. Esses indicadores, enquanto instrumentos de planejamento, possibilitam detectar desigualdades espaciais e proporcionar linhas estratégicas de ação para melhorar o bem-estar da população, principalmente nas áreas mais carentes das cidades, aproximando a qualidade de vida urbana à dimensão política.

\title{
Indicadores georreferenciados em interface com o planejamento urbano
}

As desigualdades espaciais são reflexos da influência da dinâmica capitalista no território. Segundo Vitte (2009, p.111), por ser "o produto de um processo político e social, portanto histórico, de construção e transformação da natureza pela sociedade" e "condição material reveladora das condições de vida e da maior ou menor presença do poder público na vida das pessoas e de seus lugares", o território no modo de produção capitalista "expressa-se de maneira desigual, seja na agregação de equipamentos e valor ou mesmo na densidade e qualidade da infra-estrutura e dos serviços de uso coletivo" (VITTE, 2009, p. 120).

O território também será constituído do espaço no qual as pessoas vivem - espaço vivido e de cidadania - e a compreensão dos diferentes territórios que compõem o espaço urbano será fundamental para o conhecimento da realidade social. A partir da dificuldade do Estado em garantir acesso equitativo a bens de consumo coletivo nos territórios, o desenvolvimento de indicadores de qualidade de vida urbana, que levem em consideração as diferenças territoriais, são fundamentais para compreender o território como objeto de intervenção política.

As cidades, enquanto espaço de produção e vivência, sempre foram temas de estudo nas mais diferentes áreas do conhecimento, entretanto, seus métodos de análise se 
caracterizaram, quase sempre, por generalizações que as interpretaram a partir de uma totalidade, também importante, mas que deixaram o espaço intraurbano em segundo plano. De acordo com Villaça (2001), essa situação reflete-se na pouca atenção que tem sido dispensada ao estudo do espaço intraurbano, tanto do ponto de vista teórico como empírico.

Para além das medidas caracterizadas como genéricas do espaço urbano, verificase uma tendência maior, a partir dos anos de 1990, em trazer para o debate o tema da dimensão intraurbana, que se caracteriza pela busca de uma análise das desigualdades internas dos territórios urbanos, que têm apresentado uma forte tendência à segregação socioespacial.

Nesse quadro, as regiões periféricas continuam desprovidas de condições básicas para a sobrevivência, em que o território vivido se restringe a condições precárias de habitação, negligenciando seus espaços de vivência e convivência. Para Koga (2003, p. 105), "não somente a vida cotidiana parece fragmentar-se através das distâncias que separam a casa do trabalho, dos serviços e do lazer, como também as relações sociais de proximidade parecem restringir-se".

No desenvolvimento de pesquisas de qualidade de vida urbana, a preocupação com o levantamento de dados territorializados - tendo a dimensão intraurbana como pressuposto metodológico central - é importante para romper com a produção de análises gerais baseadas na média dos dados agregados, que pouco auxilia o direcionamento efetivo de políticas públicas para redução das muitas desigualdades socioespaciais existentes, sobretudo nas grandes e nas médias cidades brasileiras.

É nesse momento que ferramentas de Geoprocessamento podem contribuir de maneira significativa para ampliar e instrumentalizar a construção desses dados. $\mathrm{O}$ Geoprocessamento enquanto área do conhecimento que utiliza técnicas matemáticas e computacionais para o tratamento da informação geográfica (CÂMARA; DAVIS, 2001) tem estabelecido diálogos crescentes com diferentes áreas, inclusive com o Planejamento Urbano, sendo que a organização de dados georreferenciados a partir de Sistemas de Informação Geográfica (SIG) aplicados ao estudo urbano é fundamental para conhecer a configuração espacial das cidades. Sobre o SIG, Leite (2006, p. 22) destaca que:

Essa técnica é um ramo do geoprocessamento bastante utilizada hoje e de suma importância para estudos geográficos de correlação, visto que consegue combinar dados de diferentes fontes e espacializar essas informações em um mapa. Portanto, o SIG é instrumento essencial para análises complexas que envolvem uma grande quantidade de dados, que depois de combinadas e processadas fornecem ao usuário 
novas informações que podem ser retiradas através de gráficos, tabelas e principalmente mapas.

Como campo crescente de estudos, sua utilização nas questões urbanas pode ser uma importante ferramenta para subsidiar ações de planejamento urbano, uma vez que permite investigar e conhecer melhor diversos fatores que impactam a qualidade de vida urbana, dentre eles, questões relacionadas à distribuição de equipamentos urbanos, desigualdades socioespaciais, problemáticas ambientais etc., que podem auxiliar o Poder Público no direcionamento de políticas urbanas integradas a outras políticas públicas para redução de problemas e contradições na configuração espacial das cidades, ou servir como fonte de informação para instrumentalizar reivindicações da própria população.

No processo de construção de indicadores, deve-se dar atenção especial à definição de unidades espaciais de cálculo para o dimensionamento das disparidades no interior dessas cidades. Segundo Nahas (2009, p.126), a construção de indicadores georreferenciados em unidades espaciais intraurbanas previamente definidas é fundamental para compreender os diferentes e desordenados processos de ocupação do solo nas cidades, que produziram um mosaico espacial profundamente desigual em múltiplos aspectos e setores, cuja compreensão "é fundamento indispensável ao planejamento municipal voltado para a formulação de políticas públicas que promovam a redução de tais desigualdades”.

Para o delineamento metodológico necessário, ressalta-se na experiência do OQVSA, a importância conferida ao tratamento dos dados coletados a partir da espacialização de seus resultados, obtida pelo georreferenciamento e produção de mapas, que possibilita recorrer a estruturas de processamento eletrônico de dados para permitir "a captura, o armazenamento, a manipulação, a análise, a demonstração e o relato de dados referenciados geograficamente" (KARRUZ; KEINERT, R.; KEINERT, T., 2002, p.101).

Outra contribuição metodológica importante é referenciada pela experiência da cidade de Curitiba, através do Projeto "Construindo Qualidade de Vida em Curitiba", que busca contemplar o maior número de áreas do contexto urbano para que o máximo das potencialidades desse espaço seja explorado e expresso em termos de indicadores de impacto na vida da população e no ambiente da cidade, vinculados a quatro grupos de necessidades avaliados: saúde, habitação, educação e transporte (RIBEIRO; MELLO, 2002). Ainda para essas autoras: 
A análise dos diferenciais intraurbanos consolida uma prática de avaliação sistemática da qualidade de vida da população urbana, visando repensar o desenvolvimento de uma cidade com contradições explícitas: de um lado, cria e organiza as estruturas que permitam seu bom funcionamento; de outro, procura dar acesso a cada habitante a uma vida digna e com qualidade (RIBEIRO; MELLO, 2002, p.182).

Destaca-se ainda a experiência da cidade de Belo Horizonte, com o desenvolvimento de um amplo sistema de indicadores que resultou na construção do Índice de Qualidade de Vida Urbana (IQVU), calculado a partir de indicadores georreferenciados nas 81 unidades de planejamento (UP) da cidade, que buscaram contemplar a oferta local de equipamentos e serviços de abastecimento alimentar, assistência social, cultura, educação, esportes, habitação, infraestrutura, saúde, segurança urbana e serviços urbanos (NAHAS, 2009).

A construção desses indicadores para a compreensão da realidade urbana nas cidades reforça a afirmação de que a preocupação com a qualidade de vida e sua mensuração pode ser um importante instrumento para dimensionar aspectos e problemas que interferem na promoção de um maior desenvolvimento no urbano. Como pontos cruciais para a monitoração da qualidade de vida a partir de indicadores intraurbanos destacam-se, entre outros, a necessidade de:

\begin{abstract}
Caracterização dos diferenciais intraurbanos do município, estabelecendo-se índices de qualidade de vida para cada microárea (bairro) e para o município como um todo, num dado período de tempo; (...) detecção das áreas que necessitam de maior intervenção, segundo os pontos de vista social, econômico, de infra-estrutura, ambiental ou de formulação de políticas específicas mais includentes; construção de mapas temáticos de maneira a propiciar uma maior visualização das faixas e distribuição da qualidade de vida da cidade; viabilização de subsídio ao planejamento urbano e criação de políticas específicas para o município; (...) disseminação de informações analíticas a respeito dos resultados totais ou locais nas áreas específicas para que essas informações estimulem a transformação da realidade local (RIBEIRO; MELLO, 2002, p.183).
\end{abstract}

A partir dessa constatação, a contribuição de indicadores intraurbanos de qualidade de vida urbana - utilizando ferramentas de geoprocessamento de dados na produção de diagnósticos de situação espacializados para seus diversos temas - mostra-se como um assunto emergente e relevante, principalmente quando associado ao novo modelo de planejamento urbano preconizado pelas diretrizes do Estatuto da Cidade (2001), no caso do Brasil, que busca uma nova lógica de universalização do acesso aos serviços e equipamentos urbanos; uma gestão para as cidades que priorize a dimensão política de participação de seus 
habitantes nos processos de planejamento; além da prevalência do interesse social sobre interesses particulares que resulte na construção de um espaço urbano mais justo e equilibrado.

\section{CONSIDERAÇÕES FINAIS}

Embora venha adquirindo relevância significativa em diversos campos, o conceito de qualidade de vida ainda mostra-se complexo devido à sua amplitude. No âmbito urbano, modelos de planejamento e gestão urbanos participativos e orientados para promoção de cidades mais justas e sustentáveis têm fortalecido sua inserção como uma temática essencial para se buscar melhorias efetivas nas condições de vida da população, o que contribui para sua fundamentação no campo conceitual e sua legitimação no campo empírico.

Nesse contexto, a preocupação com a qualidade de vida nas cidades pode ser referência para um modelo de desenvolvimento urbano que prioriza a dimensão social, aproximando a cidadania ao cotidiano urbano. Retoma a preocupação com valores humanos, em contraposição à mera quantificação da dimensão econômica predominante, contemplando aspectos materiais e imateriais, objetivos e subjetivos, individuais e coletivos, essenciais à compreensão das reais condições de vida de uma população.

A busca pela mensuração da qualidade de vida por sistemas de indicadores contempla áreas essenciais à compreensão das condições de vida de uma população, vinculadas não só a aspectos econômicos, mas que envolvem também questões ligadas ao meio ambiente, serviços urbanos, habitação, mobilidade e transporte, educação, participação política, segurança, saúde, lazer e outros; o que abre diferentes campos de pesquisa, assim como o compartilhamento de experiências e trocas de informações desses sistemas, que podem contribuir para o aprimoramento de indicadores e criação novas metodologias.

Destaca-se, ainda, a construção de sistemas de indicadores sobre qualidade de vida urbana que têm na realidade intraurbana a base de sua investigação, possibilitada por dados georreferenciados, como fundamental para produzir análises centradas no combate às desigualdades, podendo servir de base para ações de planejamento urbano, políticas públicas, mobilizações sociais, e muitas outras, na busca pela incorporação de uma vivência realmente cidadã para todos no território urbano, e não apenas para uma minoria da população. 
Além disso, a velocidade com que o campo tecnológico e das ciências informacionais têm se desenvolvido também contribui para o surgimento de novas ferramentas e plataformas que auxiliam a disseminação de usos e usuários de informações integradas de diversas fontes e bancos de dados georreferenciados, ampliando o acesso a informações articuladas por diferentes setores da sociedade, o que pode ensejar processos de empoderamento da população na reivindicação de melhores condições de vida no meio em quem vivem.

Diante desse quadro, é importante desenvolver e aprofundar pesquisas que contemplem a discussão da qualidade de vida nas cidades brasileiras, levando em consideração as desigualdades socioespaciais existentes em seu interior e, também, o potencial que as crescentes inovações no campo das tecnologias da informação geográfica podem oferecer na construção e disseminação desses indicadores.

Ao englobar diferentes áreas, a construção de indicadores para dimensionar aspectos que interferem na qualidade de vida da população pode ser mais uma ferramenta na promoção de mudanças efetivas nas cidades, tão necessárias ao desenvolvimento urbano brasileiro.

\section{REFERÊNCIAS}

BRASIL. Congresso Nacional. Lei n. 10.257 de 10 de julho de 2001(Estatuto da Cidade). Regulamenta os artigos 182 e 183 da Constituição Federal, estabelece diretrizes gerais da política urbana e dá outras providências. Disponível em:

<http//:www.planalto.gov.br/CCIVIL/LEIS_2001/L10257.htm>. Acesso em: Maio, 2008.

CÂMARA, Gilberto; DAVIS, Clodoveu. Apresentação. In:

MONTEIRO, Miguel (Orgs.) Introdução à Ciência da Geoinformação. 2001. Disponível em: <http://www.dpi.inpe.br/gilberto/livro/introd/index.html>. Acesso em Jun., 2016.

CARVALHO, S. N. de. Condicionantes e Possibilidades Políticas do Planejamento Urbano. In: VITTE, C. C. S.; KEINERT, T. M. M. (Orgs.) Qualidade de Vida, Planejamento e Gestão Urbana: discussões teórico-metodológicas. Rio de Janeiro, Bertrand Brasil, 2009. p.21-67.

HERCULANO, Selene. A qualidade de vida e seus indicadores. In: Revista Ambiente e Sociedade, Campinas, UNICAMP/NEPAM, Ano I, n², $1^{\circ}$ semestre de 1998. p.01-24.

JANUZZI, Paulo. Repensando a prática de uso de indicadores sociais na formulação e avaliação de políticas públicas municipais. In: KEINERT, Tânia; KARRUZ, Ana Paula 
(Orgs.) Qualidade de Vida: observatórios, experiências e metodologias. São Paulo: Annablume: Fapesp, 2002. p.53-71.

Indicadores Sociais no Brasil: conceitos, fontes de dados e aplicações.4. ed. Campinas, SP: Editora Alínea, 2009. 141 p.

KARRUZ, Ana Paula; KEINERT, Ruben; KEINERT, Tânia. O processo de construção do Observatório de Qualidade de Vida de Santo André: identificação e superação de desafios. In: KEINERT, Tânia; KARRUZ, Ana Paula (Orgs.) Qualidade de Vida: observatórios, experiências e metodologias. São Paulo: Annablume: Fapesp, 2002. p.95-105.

KOGA, Dirce. Medidas de Cidades: entre territórios de vida e territórios vividos. São Paulo: Cortez, 2003. 299 p.

LEFÈBVRE, Henri, Espaço e Política. Belo Horizonte: Editora UFMG, 2008 (1972). 192 p.

LEITE, Marcos. Geoprocessamento aplicado ao estudo do espaço urbano: o caso da cidade de Montes Claros. 2006, 106f. Dissertação (Mestrado em Geografia). Programa de PósGraduação em Geografia. Universidade Federal de Uberlândia. Uberlândia, 2006.

MARICATO, Ermínia. Metrópole, legislação e desigualdade. Estudos Avançados, São Paulo, v. 17, n. 48,Ago. 2003. Disponível em:<http://www.scielo.br $>$ Acesso em: 25 nov. 2010.

MARQUES, Renato. Esporte e Qualidade de Vida: reflexão sociológica. 2007. 160f. Dissertação (Mestrado em Educação Física) - Faculdade de Educação Física. Universidade Estadual de Campinas, Campinas, 2007.

NAHAS, Maria Inês. Qualidade de vida urbana em números. ComCiência (UNICAMP), v.96, p.96, 2008.

Indicadores Intra-Urbanos como instrumentos de gestão da qualidade de vida urbana em grandes cidades: uma discussão teórico-metodológica. In: VITTE, Claudete; KEINERT, Tânia(Orgs.) Qualidade de Vida, Planejamento e Gestão Urbana: discussões teórico-metodológicas.Rio de Janeiro, Bertrand Brasil, 2009. p.123-153.

RIBEIRO, Ângela; MELLO, Terezana. Aferindo qualidade de vida: a experiência de Curitiba. In: KEINERT, Tânia; KARRUZ, Ana Paula (Orgs.). Qualidade de Vida: observatórios, experiências e metodologias. São Paulo: Annablume: Fapesp, 2002. p.179-187.

SOUZA, Marcelo. Mudar a cidade: uma introdução crítica ao planejamento e à gestão urbanos.5.ed. Rio de Janeiro: Bertrand, 2008. 560 p.

VILLAÇA, Flávio.Espaço intra-urbano no Brasil. São Paulo: Studio Nobel, 1998. 376 p.

VITTE, Antônio. Modernidade, Território e Sustentabilidade: refletindo sobre qualidade de vida. In: VITTE, Claudete; KEINERT, Tânia(Orgs.) Qualidade de Vida, Planejamento e Gestão Urbana: discussões teórico-metodológicas. Rio de Janeiro, Bertrand Brasil, 2009. p.111- 122 . 
VITTE, Claudete. Planejamento urbano, sustentabilidade urbana e qualidade de vida: considerações sobre o significado de cidade e de cidadania no início do século XXI. In: KEINERT, Tânia; KARRUZ, Ana Paula (Orgs.) Qualidade de Vida: observatórios, experiências e metodologias. São Paulo: Annablume: Fapesp, 2002. p.21- 38.

VITTE, Claudete; KEINERT, Tânia. Apresentação. In: (Orgs.) Qualidade de Vida, Planejamento e Gestão Urbana: discussões teórico-metodológicas. Rio de Janeiro, Bertrand Brasil, 2009. p. 09-11.

YUAN, Lim; YUEN, Belinda; LOW, Christine. Quality of life in cities - Definition, Approches and Research. In : Urban Quality of Life : critical issues and options. Singapura, National University of Singapore, 1999.p.01- 12.

\section{Autora}

Isabela Veloso Lopes Versiani - Possui Graduação em Educação Física e em Ciências Sociais pela Universidade Estadual de Montes Claros (UNIMONTES), Mestrado em Desenvolvimento Social pela Universidade Estadual de Montes Claros (UNIMONTES). Atualmente é Docente do Departamento de Educação Física das Faculdades Integradas do Norte de Minas (FUNORTE).

Artigo recebido em: 30 de julho de 2016.

Artigo aceito em: 16 de setembro de 2016. 